\title{
EDITORIAL
}

\section{Rigor and Relevance}

As Personnel Psychology enters its $66^{\text {th }}$ year, the journal is arguably stronger than ever. Manuscript submissions grow each year and increasingly come from scholars located around the globe. Article downloads from Wiley Online also continue to rise, and the journal is widely read. Further, $P$-Psych continues to publish research that is both rigorous and relevant, and it remains one of the most highly cited journals in applied psychology and management. These accomplishments are particularly noteworthy given the rise in scholarly outlets in our field. Between 2004 and 2012, the number of applied psychology journals listed in the Journal Citation Reports, Social Science Edition increased by $46 \%$ (50 to 73 ), while the number of management journals increased $160 \%$ (67 to 174 ).

As the incoming editorial team, our goal is to build on this position of strength and to advance both the reputation and readership of the journal. One way in which we intend to do this is by staying true to the mission that has guided P-Psych since its inception, which is to publish rigorous psychological research centered around people at work. Over the years, this focused mission has enabled the journal to publish seminal articles in personnel selection (Barrick \& Mount, 1991), person-organization fit (Schneider, 1987), organizational citizenship behavior (Organ \& Ryan, 1995), and many other areas of industrial-organizational psychology, human resource management, and organizational behavior. In addition, articles that have recently appeared in the journal have helped to shape current thinking about a diversity of workplace topics, including leadership (DeRue, Nahrgang, Wellman, \& Humphrey, 2011), work engagement (Christian, Garza, \& Slaughter, 2011), work-family conflict (Kossek, Pichler, Bodner, \& Hammer, 2011), and strategic human resource management (Chuang \& Liao, 2010).

Our editorial team also plans to leverage the unique features that distinguish $P$ - Psych from other applied psychology and management journals. One such feature is our emphasis on publishing research that has high levels of organizational relevance. We seek research that focuses on the 
challenges facing today's organizations (private and public sector; profit and nonprofit) and that offers practical implications for organizations and the individuals, managers, and teams embedded within them. These are complex and multifaceted challenges that need to be studied using different approaches and perspectives. Thus, $P$ - Psych will continue to be open to many different types of research. This includes quantitative and qualitative research as well as studies that are conducted in different research settings (e.g., field, laboratory) and at different levels of analysis (e.g., individual, team, organizational). Investigations that examine a phenomenon across multiple settings or that cut across multiple levels of analysis are particularly encouraged. We are interested in original empirical research, theory development, meta-analytic reviews, and narrative literature reviews. Finally, we seek research spanning the full range of human resource management and organizational behavior topics, including research that focuses on areas of emerging importance. The two most recent issues of the journal have focused attention on two such areas - corporate social responsibility and the global context - and we will continue to use special and virtual issues to put the spotlight on other emerging topics.

The current strength of P-Psych has been built on the dedication of past editors of the journal. I feel privileged to be following an exceptional editorial team, led by Frederick Morgeson. During his term, Frederick has not only strengthened the connection to our past but has also pushed the journal in new and exciting directions. I also want to thank Maria Kraimer, Hui Liao, and Chad Van Iddekinge, and the previous editorial board for their hard work and dedication. The new editorial team started receiving submissions on January $1^{\text {st }}, 2014$. This new team includes me and four associate editors: Wendy Boswell (Texas A\&M University), Berrin Erdogan (Portland State University), John Hausknecht (Cornell University), and Nathan Podsakoff (University of Arizona). I feel very fortunate to have been able to assemble such an outstanding group of associate editors. They were chosen based on their research productivity in P-Psych (each has published multiple times in the journal), their research productivity in other top outlets, the applied nature of their research, and their exceptional 
performance while serving as members of the editorial board. The new editorial board includes 75 accomplished scholars that have consistently delivered timely and high quality feedback on the manuscripts they have reviewed for P-Psych. Over time, we will add a small number of scholars to the editorial board to recognize excellent ad-hoc reviewing and to ensure that we have the expertise available to cover the variety of manuscripts that we receive.

The editorial process will follow the same model that has been in place for the past several years. Submitted manuscripts will first be checked to ensure that they adhere to our submission guidelines and then will be given to me. I will then read the manuscript and determine whether it should be sent out for double-blind review. Manuscripts that fall outside of the journal's mission will be desk rejected, whereas manuscripts that are not properly formatted or require further refinement before they undergo review will be returned to authors for editing and resubmission. I will assign all other manuscripts to an action editor and at least two reviewers who are experts in the topic area. The reviewers submit their recommendations to the action editor who then makes the final decision on the manuscript.

The reviewers' recommendations and the action editor's publication decision are based on an evaluation of the article's contribution on three dimensions. The first is theoretical contribution, or whether the article offers new and innovative ideas and insights or meaningfully extends existing theory. The second is empirical contribution, which considers whether the article offers new and unique findings and whether the study design, data analysis, and results are rigorous and appropriate in testing the research questions. The final dimension is practical contribution, which focuses on whether the article contributes to the improved management of people at work. Although we expect most articles to make a contribution in all three areas, the relative emphasis that each receives will vary from article to article. A narrative review, for example, may make a much stronger contribution to the theoretical domain, whereas the primary contribution of other articles may reside in a set of unique findings 
(empirical contribution) or an elegant solution to a critical organizational challenge (practical contribution).

We appreciate the time and energy that authors put into their work. Accordingly, one of our most important goals as an editorial team is to ensure that every author has a positive experience during the review process at $P$-Psych, regardless of the specific outcome at our journal. We are committed to providing authors with feedback on their manuscripts within 60 days of submission and to making final decisions regarding publication after either a first or second revision. In addition, we will provide detailed and constructive feedback so that authors know not only what we see as the major strengths and weaknesses of the manuscript but also how to potentially improve their research. Finally, we will publish accepted articles in a timely fashion (both online and in print) and we will strive to enhance the visibility of these articles in both the academic and practitioner communities.

Our editorial team is excited about the future of $P$-Psych. We look forward to building upon the journal's distinguished history while also ensuring that it continues to publish theoretically and empirically rigorous research that is highly relevant to the challenges facing today's organizations. We look forward to receiving your submissions.

Bradford S. Bell Editor, Personnel Psychology brad.bell@cornell.edu 


\section{References}

Barrick, M. R., \& Mount, M. K. (1991). The Big Five personality dimensions and job performance: A metaanalysis. Personnel Psychology, 44, 1-26.

Christian, M. S., Garza, A. S., \& Slaughter, J. E. (2011). Work engagement: A quantitative review and test of its relations with task and contextual performance. Personnel Psychology, 64, 89-136.

Chuang, C., \& Liao, H. (2010). Strategic human resource management in service context: Taking care of business by taking care of employees and customers. Personnel Psychology, 63, 153-196.

DeRue, D. S., Nahrgang, J. D., Wellman, N., \& Humphrey, S. E. (2011). Trait and behavioral theories of leadership: An integration and meta-analytic test of their relative validity. Personnel Psychology, $64,7-52$.

Kossek, E. E., Pichler, S., Bodner, T., \& Hammer, L. B. (2011). Workplace social support and work-family conflict: A meta-analysis clarifying the influence of general and work-family-specific supervisor and organizational support. Personnel Psychology, 64, 289-313.

Organ, D. W., \& Ryan, K. (1995). A meta-analytic review of attitudinal and dispositional predictors of organizational citizenship behaviors. Personnel Psychology, 48, 775-802.

Schneider, B. (1987). The people make the place. Personnel Psychology, 40, 437-453. 